Review

\title{
Salmonella-Mediated Cancer Therapy: An Innovative Therapeutic Strategy
}

\author{
Ze Mi, Zhi-Chao Feng, Cheng Li, Xiao Yang, Meng-Tian Ma, Peng-Fei Rong ${ }^{\bowtie}$ \\ Department of Radiology, The Third Xiangya Hospital, Central South University, Changsha, Hunan 410013, China \\ $\bowtie$ Corresponding author: Email: rongpengfei66@163.com \\ (C) The author(s). This is an open access article distributed under the terms of the Creative Commons Attribution License (https://creativecommons.org/licenses/by/4.0/). \\ See http://ivyspring.com/terms for full terms and conditions.
}

Received: 2018.12.28; Accepted: 2019.07.06; Published: 2019.08.20

\begin{abstract}
Bacterial-mediated cancer therapy (BMCT) has become a hot topic in the area of antitumor treatment. Salmonella has been recommended to specifically colonize and proliferate inside tumors and even inhibit tumor growth. Salmonella typhimurium (S. typhimurium) is one of the most promising mediators, which can be easily manipulated. S. typhimurium has been engineered and designed as cancer-targeting therapeutics, and can be improved by combining with other therapeutic methods, e.g. chemotherapy and radiotherapy, which regulate the tumor microenvironment synergistically. In view of all these strengths, the engineered attenuated strains have significant advantages for tumor diagnosis and treatment. This treatment has also been approved by the FDA for clinical trial. In this review, we summarized the recent progress and research in the field of Salmonella-mediated cancer therapy.
\end{abstract}

Key words: bacterial-mediated cancer therapy, Salmonella, tumor microenvironment, combination therapy

\section{Introduction}

Cancer has become a serious disease for modern societies [1]. Every cancer patient is expected to receive an effective diagnosis and treatment of the tumor within a life time [2]. Although conventional therapies, including surgery, chemotherapy and radiotherapy, remain the most common treatments for cancer, the limitations of these treatments have become increasingly apparent. Therefore, some novel strategies are needed to treat the tumor. Surgery is an effective treatment for tumors; however, relapse and metastasis may make surgery more difficult and risky in treating malignant tumors [3]. The efficacy of radiotherapy depends mainly on causing DNA damage in tumor cells. Tissue oxygen levels play an important role during treatment. Studies have shown that low oxygen concentrations in hypoxic and necrotic regions are a common cause of treatment failure [4]. On the other hand, the distribution of a drug is important for the therapeutic effect of chemotherapy, and the poor vasculature in tumors impairs drug delivery, especially in necrotic and hypoxic regions [5]. Apparently, a single method cannot achieve a cure for a tumor, and different methods should be used in combination to compensate for the respective deficiencies, representing the inevitable development trend of tumor therapeutics.

In recent years, Bacterial-mediated cancer therapy (BMCT) has become the hotspot in recent research, and many attenuated bacteria produced by genetic engineering can target tumors and have local antitumor effects. BMCT has been investigated as therapeutic for over 100 years since the bone surgeon William B. Coley injected Streptococcus pyogenes into patients with inoperable bone and soft-tissue sarcomas [6]. This treatment successfully shrunk the tumors and increased patient survival [7]. However, the lack of progressive techniques and modalities to diagnose tumors and quantify changes in immune responses resulted in a poor understanding of the underlying mechanisms and difficulties in explaining Coley's results. With the development of medical technology, especially in genetic engineering, BMCT has again become a hot topic, and various kinds of bacteria, such as Streptococcus[8], Bifidobacterium[9], Clostridium[10], and S. typhimurium[11, 12]. 
S. typhimurium can grow under both aerobic and anaerobic conditions and thus has the capability to target and colonize nonhypoxic and hypoxic tumors as well as metastatic tumor regions accessible by the circulatory system. As a new antitumor treatment, $S$. typhimurium makes up for the gap in chemotherapy and radiotherapy in hypoxic and necrotic regions. $S$. typhimurium preferentially accumulates within tumors, forming tumor-to-normal tissue ratios exceeding 1000-10,000 to 1 , and these microbes are the most efficient antitumor bacteria assayed in experimental models of cancer thus far [13, 14]. Immunotherapy based on Salmonella has a specific "Trojan horse" tumor-attack feature, which has been used in treatment-resistant tumors [15-17]. Why do $S$. typhimurium strains have significant targeting and tumor-suppressing abilities? This mechanism will be covered in more detail later in this article. Furthermore, S. typhimurium can combine with radiotherapy [18, 19] and chemotherapy [20-22]. Combined Salmonella has already become the present research focus in the treatment of tumors. Salmonella-mediated antitumor therapy has the prospect to be a breakthrough to cancer therapy.

\section{S. typhimurium Laboratory Strains for Cancer Therapy}

Numerous S. typhimurium mutant strains have been studied from the perspective of cancer treatment. S. typhimurium laboratory strains have been designed to reduce cytotoxic effects in normal organs, increase specific targeting for tumors and enhance antitumor abilities [23-25]. Herein, we focused on the most common and recognized laboratory strains, VNP20009, A1-R, and $\Delta$ ppGpp. A list of the most common mutations and their potential biological mechanisms in various tumors is described in Table 1. We also introduced some other strains in this review.

\section{VNP20009}

VNP20009 is the only Salmonella strain to be evaluated in a phase I clinical trial in humans [26], and it has been widely studied in animal cancer models. VNP20009 is a genetically modified S. typhimurium strain possessing an excellent safety profile. To genetically attenuated virulence, the purI gene was deleted. To reduce septic shock potential and antibiotic susceptibility, the msbB gene was also deleted. VNP20009 keeps its phenotypic and genetic stability after multiple generations both in vitro and in vivo. VNP2009 can colonize and proliferate in tumor tissues very well. In tumor-modeling mice, VNP20009 accumulates preferentially in tumor tissues over normal organs at a ratio of $>1000: 1$. After that experiment, VNP20009 was cleared from the blood and organs within $24 \mathrm{~h}$ by the immune system [27, 28]. Recently, VNP20009 has been sequenced for other genes to improve tumor targeting. Aside from the known purI and msbB gene deletions, other mutations have also been found, including a 108-kb Suwwan deletion, 50 nonsynonymous SNPs, a purM deletion and a derivative $\Delta$ htrA [29, 30]. More research is needed to prove their effectiveness and stability.

\section{AR-1}

By using nitrosoguanidine mutagenesis, the AR-1 strain was developed. The AR-1 strain was recovered from this selection and identified as an arginine and leucine auxotroph [31]. S. typhimurium AR-1 has a similar function as VNP20009. In addition to the tumors in Table 1, AR-1 also inhibited the growth of different cancers in mouse models of glioma[32], prostate cancer[33], pancreatic cancer[34], and cervical cancer[35], and inhibited metastasis [36, 37]. Most of the latest research shows that the AR-1 strain can cause the progression of tumor cells in the cell cycle from G0/G1 to S/G2/M, therefore increasing their sensitivity to combinational chemotherapy [38]. Many studies have demonstrated that cytotoxic chemotherapy kills only tumor cells in the S/G2/M phase, which are the minority in an established tumor, and has little effect on cancer cells in the G0/G1 phase $[39,40]$.

\section{$\Delta$ ppGpp}

This avirulent $S$. typhimurium strain was designed by regulating endotoxin gene expression. The relA and SpoT double mutant Salmonella was defective in ppGpp synthesis and tested avirulent in extensive mouse models. Safety tests showed that the LD50 values with the mutant were $1 * 10^{5}$ higher than those of the wild type after oral or intraperitoneal inoculation. $\Delta$ ppGpp achieved excellent cancer suppression by activating the inflammasome pathway $[16,41]$. This attenuated strain showed very high tumor targeting and the stimulation of regional tumor immunity. These mutant strains can induce tumor cells to secrete antitumor cytokines, such as IL-1 $\beta$, IL-18, and TNF-a, thereby suppressing the proliferation of tumor models in mice. However, these cytokines have double effects on tumor cells. At low concentrations, these cytokines can stimulate and promote tumor growth. On the other hand, while normally produced at a high concentration, these cytokines can suppress tumor development [42, 43]. The engineered bacteria can also express imaging reporter genes, such as Renilla and firefly luciferases $[44,45]$. 
Table 1 The most common S. typhimurium strains for targeted cancer therapy

\begin{tabular}{|c|c|c|c|c|c|c|c|c|}
\hline Strains & Genotype & Target tumors & Model & Injection route & $\begin{array}{l}\text { Combined with other } \\
\text { therapies }\end{array}$ & Mechanism & $\begin{array}{l}\text { In necrotic } \\
\text { region } \\
(\text { Yes/No) }\end{array}$ & References \\
\hline \multirow[t]{7}{*}{ VNP20009 } & $\begin{array}{l}\Delta \text { purI } \\
\Delta \mathrm{msbB}\end{array}$ & Melanoma & C57BL/6 mice & Intraperitoneal & IL-21 & $\begin{array}{l}\text { IL-12 induced more NK and T cells } \\
\text { to the tumor areas }\end{array}$ & Yes & [12] \\
\hline & & & 24 patients & Intravenous & & & & [26] \\
\hline & & & C57BL/ 6 mice & Intravenous & Photothermal Therapy & $\begin{array}{l}\text { Incident light heats and kills the } \\
\text { tumor cells }\end{array}$ & Yes & [52] \\
\hline & & & C57BL/6 mice & Intravenous & Hydroxychloroquine & Autophagy-mediated antitumors & Yes & [53] \\
\hline & & & C57BL/6 mice & Intravenous & Triptolide & $\begin{array}{l}\text { Modulating tumor angiogenesis } \\
\text { and the host immune response }\end{array}$ & Yes & [54] \\
\hline & & Breast cancer & $\mathrm{BALB} / \mathrm{c}$ mice & Intravenous & & Expressing the cytokine CCL21 & Yes & [55] \\
\hline & & Lung cancer & BALB/c mice & Intravenous & Antiangiogenesis peptide & $\begin{array}{l}\text { VNP20009 carrying a Sox } 2 \text { shRNA } \\
\text { construct }\end{array}$ & Yes & \\
\hline \multirow[t]{6}{*}{ AR-1 } & $\begin{array}{l}\text { arginine } \\
\text { and leucine }\end{array}$ & Melanoma & $\begin{array}{l}\text { Athymic nu/nu } \\
\text { nude mice }\end{array}$ & Intravenous & $\begin{array}{l}\text { Recombinant } \\
\text { Methioninase (MET) }\end{array}$ & $\begin{array}{l}\text { MET restriction arrests cancer cells } \\
\text { in late } S / G 2 \text { of the cell cycle }\end{array}$ & Yes & [56] \\
\hline & auxotroph & & $\begin{array}{l}\text { Athymic nu/nu } \\
\text { nude mice }\end{array}$ & Intravenous & $\begin{array}{l}\text { Vemurafenib or } \\
\text { temozolomide }\end{array}$ & & Yes & [21] \\
\hline & & $\begin{array}{l}\text { Gastrointestinal } \\
\text { stromal tumor }\end{array}$ & $\begin{array}{l}\text { Athymic nu/nu } \\
\text { nude mice }\end{array}$ & Intravenous & & $\begin{array}{l}\text { AR-1 decoys quiescent tumor cells } \\
\text { from } \mathrm{G} 0 / \mathrm{G} 1 \text { to } \mathrm{S} / \mathrm{G} 2 / \mathrm{M} \text { phase }\end{array}$ & Yes & [57] \\
\hline & & Pancreatic cancer & $\begin{array}{l}\text { Athymic nu/nu } \\
\text { nude mice }\end{array}$ & Intravenous & Gemcitabine & $\begin{array}{l}\text { AR-1 decoys quiescent tumor cells } \\
\text { from } \mathrm{G} 0 / \mathrm{G} 1 \text { to } \mathrm{S} / \mathrm{G} 2 / \mathrm{M} \text { phase }\end{array}$ & Yes & [58] \\
\hline & & & $\begin{array}{l}\text { Athymic nu/nu } \\
\text { nude mice }\end{array}$ & Intravenous & & $\begin{array}{l}\text { AR-1 promotes tumoricidal CD8+ } \\
\text { T cell tumor infiltration }\end{array}$ & Yes & [59] \\
\hline & & $\begin{array}{l}\text { Osteosarcomas } \\
\text { lung metastasis }\end{array}$ & $\begin{array}{l}\text { Athymic nu/nu } \\
\text { nude mice }\end{array}$ & Intravenous & $\begin{array}{l}\text { Methioninase and } \\
\text { cisplatinum }\end{array}$ & $\begin{array}{l}\text { A1-R decoys chemoresistant } \\
\text { quiescent cells to cycle }\end{array}$ & Yes & [60] \\
\hline \multirow[t]{2}{*}{$\Delta p p G p p$} & $\begin{array}{l}\Delta \mathrm{relA} \\
\Delta \mathrm{SpoT}\end{array}$ & $\begin{array}{l}\text { Colon } \\
\text { adenocarcinoma }\end{array}$ & BALB/c mice & Intravenous & & $\begin{array}{l}\text { Salmonella suppresses tumors via } \\
\text { interleukin- } 1 \beta\end{array}$ & Yes & [42] \\
\hline & & & BALB/c mice & Intravenous & Radiotherapy & & Yes & [18] \\
\hline
\end{tabular}

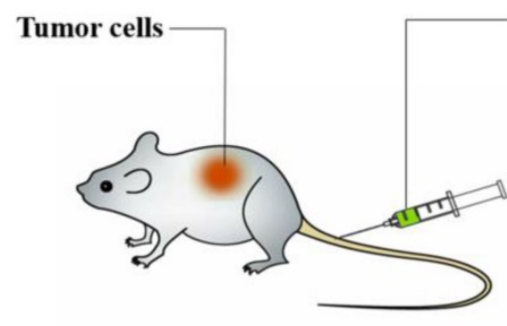

Before injection

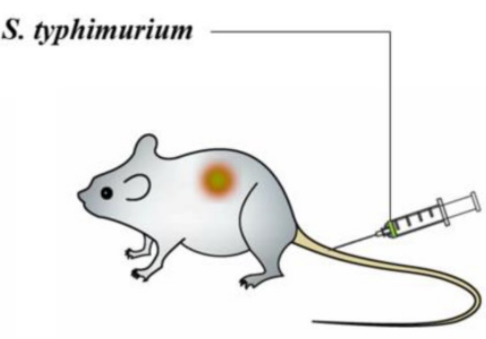

Injecting

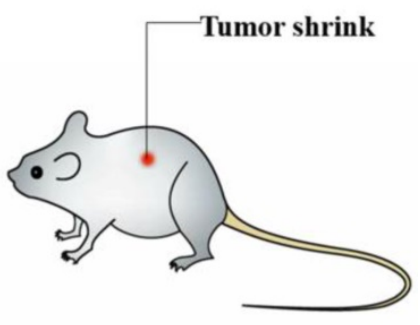

After injection

Figure 1. Schematic depiction of Salmonella-mediated cancer therapy. When administered to tumor-bearing animals, the bacteria will preferentially accumulate within tumors, especially in the nonhypoxic and hypoxic regions. Then, this treatment could obviously shrink the tumors and prolong life survival in animal models.

\section{Others}

The three strains described above represent attenuated S. typhimurium, which has been very well studied with respect to cancer therapy. But beyond that, there are other mutant strains. To engineer such bacteria with better performance, we usually combine different strategies, for example SB842 (aroA, sptP)[46], MvP728 (purD, htrA)[47], SL (aroA)[48-50], and YB1 [51]. In the future, we believe that an optimized balance will be achieved by the careful selection of genetic manipulations to achieve the appropriate attenuation and optimization of therapeutic benefit within the $S$. typhimurium mutant strains.

\section{Successful examples of Salmonella-Mediated Cancer Therapy}

Among bacteria used for cancer treatment, Salmonella shows good therapeutic effects in both solid and metastatic tumors (Figure 1). Salmonella is highly regarded because of its tumor-specific localization, its ability to target various types of tumors, a fully sequenced genome, and its natural toxicity [61].

Despite the numerous advantages of Salmonellamediated antitumors, the results are not satisfying in the phase I clinical trial. Single therapy using Salmonella, chemotherapy or radiotherapy is generally insufficient to completely cure or significantly suppress cancer growth. Therefore, nowadays, 
Salmonella combined with other therapies would be more effective in treating tumors.

\section{Combined with Chemotherapy Drugs}

Chemotherapy for tumors is partly limited by the poor vasculature in tumors due to drug delivery impairment, especially in necrotic and hypoxic regions. Salmonella is capable of preferentially replicating in these poorly perfused regions. Many studies have proven that Salmonella combines with chemotherapeutic agents, and the results are promising [54, 62-64]. The $S$. typhimurium mutant strain, VNP20009, was combined with cyclophosphamide (CTX) in a murine melanoma model. The research showed that VNP20009 significantly improved the effects of CTX treatments. The combination of CTX and VNP20009 led to a significant reduction in tumor serum vascular endothelial growth factor and capillary density compared with either treatment alone. On the other hand, combination chemotherapeutic treatment dramatically improved the number of VNP20009 within tumors when compared with bacteria treatment alone [22]. Similar results were found when AR-1 combined with temozolomide or gemcitabine significantly suppressed tumor growth compared with either AR-1 alone or the chemotherapeutics alone in a mouse tumor model [58].

However, the mechanism underlying this phenomenon is uncertain. Recent studies have suggested that there are three main views to explain this interaction. 1): As mentioned in the AR-1 strains, AR-1 can decoy quiescent cancer cells to cycle to S/G2/M. However, cytotoxic chemotherapy kills only cancer cells in the S/G2/M phase and has little effect on cancer cells in the G0/G1 phase. Therefore, the combination of AR- 1 could sensitize tumor cells to cytotoxic chemotherapy. 2): Salmonella enhances chemosensitivity in tumors through connexin 43 upregulation (Figure 2). Gap junctions mediate cell communication by allowing the connexons from one cell to another. Connexons comprise six connexin (Cx) proteins. $\mathrm{Cx} 43$ is ubiquitous and reduced in a variety of cancer cells. Cx43 may influence the response of tumor cells to treatments by facilitating the passage of antitumor drugs or death signals between neighboring tumor cells. Many cancer cells are characterized by low expression of Cx43. Salmonella can activate the expression of Cx43 in melanoma cells. Cx43 can increase the susceptibility of tumor cells to chemotherapeutic-induced cell death. 3): Salmonella overcomes drug resistance in tumors through P-glycoprotein (P-gp) downregulation (Figure 2). Many studies have proven that P-gp is a multidrug resistance transporter [20]. Recent reports have linked the overexpression of $\mathrm{P}$-gp to adverse treatment effects in many cancers. This study found that the colonization of human colon tumor cell lines by Salmonella leads to a significant decrease and loss of protein expression in P-gp. Furthermore, these authors found the $S$. typhimurium type III secreted effector protein SipA as the key influencing factor responsible for modulating P-gp through a pathway involving caspase-3. They demonstrated that the suppression of P-gp by Salmonella can be achieved within cancer to enhance the efficacy and cytotoxicity of chemotherapy drugs [65].

\section{Combined with Radiotherapy}

Radiotherapy is used to treat up to $50 \%$ of cancer patients [66]. Radiotherapy for tumors works by causing DNA damage in tumor cells, particularly DNA double-strand breaking. This damage results from ionizations in the DNA that produce a radical on the DNA. DNA damage is largely dependent on the oxygen concentration in the tumor tissue. Clinical trials have proven that markedly hypoxic tumors are more radioresistant than less hypoxic tumors. Hypoxia ( $<1 \%$ oxygen) is a near-universal feature of tumors, making these cells particularly resistant to radiotherapy. This drawback limits treatment efficacy and is associated with increased mortality and morbidity. Moreover, preclinical studies in some tumor models have suggested that radiotherapyinduced changes may promote tumor invasion and spread in certain situations - even though decades of clinical experience have failed to show clear proof that radiotherapy promotes invasion and metastasis in patients [67]. Thus, attempts to combine radiotherapy with new biologically targeted modalities were often predicated on their potential to enhance radiotherapy-induced cancer cell death rather than their potential to re-engineer biological processes within the tumor microenvironment. Salmonella may inhibit T-regulatory cells ( $\mathrm{T}_{\text {reg }}$ cells), thereby increasing the CD8 T-cell to $\mathrm{T}_{\text {reg }}$ ratios to overcome the resistance of radiotherapy [68].

Nevertheless, Salmonella has unique properties that can be radioresistant. Recently, some studies proved that radiotherapy combined with an engineered Salmonella inhibited tumor growth compared with either radiotherapy alone or Salmonella alone in a mouse model of colon cancer [9]. The mechanism underlying this combined treatment is not clear. A previous study indicated that the combination of Escherichia coli-mediated cytolytic therapy and radiotherapy inhibited tumor growth and metastasis [61]. In addition, cell stroma and immune modulation also play important roles in radiotherapy resistance [4]. These roles may include 
many mechanisms that we still do not understand (Figure 2).

\section{Combined with Other Therapies}

Given the multifactorial nature of cancer, a single treatment modality is often limited, and an increasing number of new treatments have been combined with Salmonella to treat tumors. The combination of the tumor-targeting ability of VNP20009 and photothermal therapy achieves enhanced specificity and antitumor effectiveness. A photothermal agent, such as melanin-like polydopamine (pDA), was coated with VNP20009 targeted to hypoxic and necrotic tumor areas. Then, a mouse model of the tumor was irradiated with a near-infrared laser, which achieved tumor targeting and tumor elimination without relapse or metastasis (Figure 3)[52]. Chinese medicine treatment of tumors is also a hot topic. Triptolide with VNP20009 could significantly enhance antitumor activity by modulating tumor angiogenesis and the host immune response [54]. In contrast, combining DNA vaccines and autotransporters in attenuated Salmonella-treated tumors yielded a good effect [69, 70]. We can make full use of the good targeting and the changes in the tumor microenvironment of Salmonella, combined with other treatments to achieve good results for tumor treatment, providing a new understanding of the strategy to improve antitumor therapy.

\section{Potential Cellular and Molecular mechanisms of Salmonella-Mediated Cancer Therapy}

Salmonella has been employed as antitumor agents that are capable of preferentially assembling within tumors and inhibiting their growth (Figure 4). However, the mechanisms of Salmonella-mediated cancer therapy remain unclear. Some studies have found that bacteria-derived factors have an immune-stimulation effect [71]. Moreover, it has been reported that Salmonella may have a direct antitumor effect $[72,73]$. Therefore, understanding Salmonellamediated cancer therapy mechanisms will dramatically improve the therapeutics in clinical studies.

\section{Competitive Inhibition by Salmonella}

Salmonella can specifically migrate to the cancer region, which is essential for Salmonella-mediated antitumors [23]. Some studies have demonstrated many mechanisms, including the aspartate receptor, the serine receptor, and the galactose/ribose receptor on the Salmonella surface, which attracted Salmonella toward tumor cells [74]. Strains lacking proper flagella constructs, active motor function, or signal transduction proteins lose the tropism for the tumor region [75]. In addition, bacterial metabolism and host macrophages also play an important role in the bacterial distribution and colonization in tumor cells [76]. Salmonella specifically accumulates and proliferates in tumor tissues over normal organs at a ratio of $>1000: 1$ [77]. Therefore, large numbers of Salmonella colonize the tumor area. The bacterial colonization of tumor tissues deprives tumor cells of nutrients, enhances antitumor chemokines, and activates antitumor immunity, leading to cancer cell death (Figure 5A)[78].

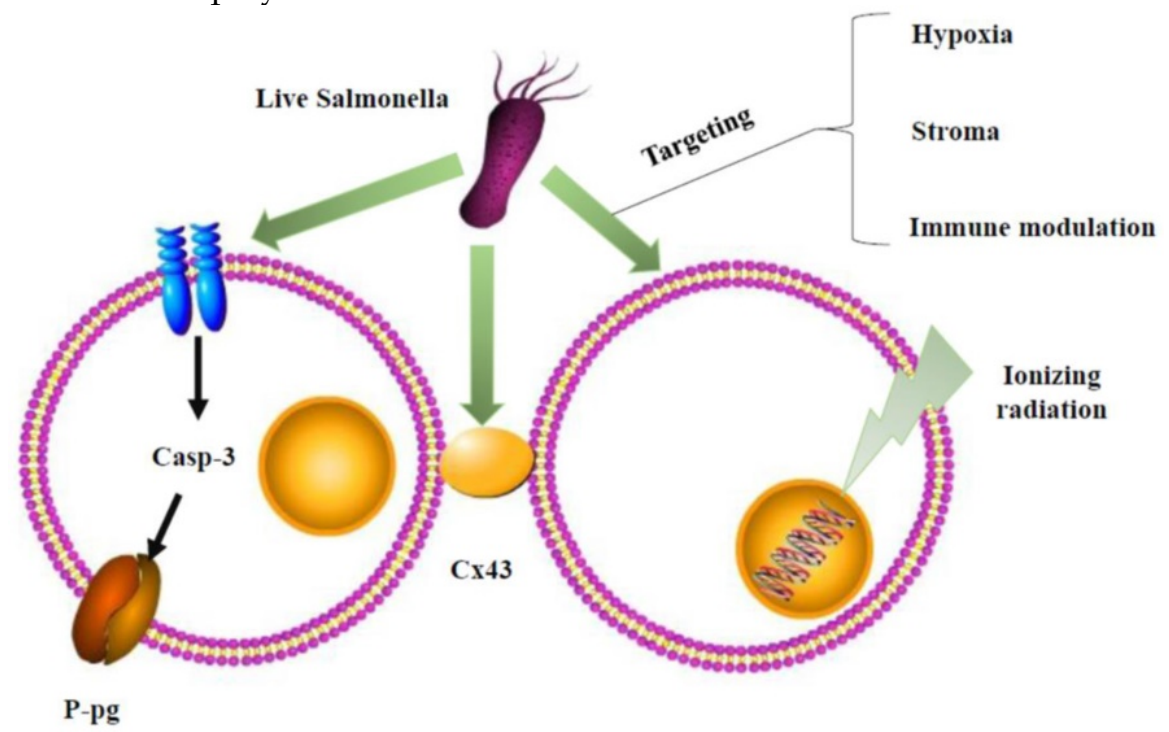

Figure 2. Schematic depiction of combination therapy for Salmonella. Salmonella could affect P-glycoprotein (P-gP) by the caspase-3 (casp-3) pathway or gap junctions, connexin 43 (Cx43), of cancer cells to enhance chemosensitivity. The underlying mechanisms of Salmonella overcome radioresistance in cancers. Salmonella changed the tumor microenvironment by hypoxia, stroma, and immune modulation to enhance radiotherapy-induced cancer cell damage. 

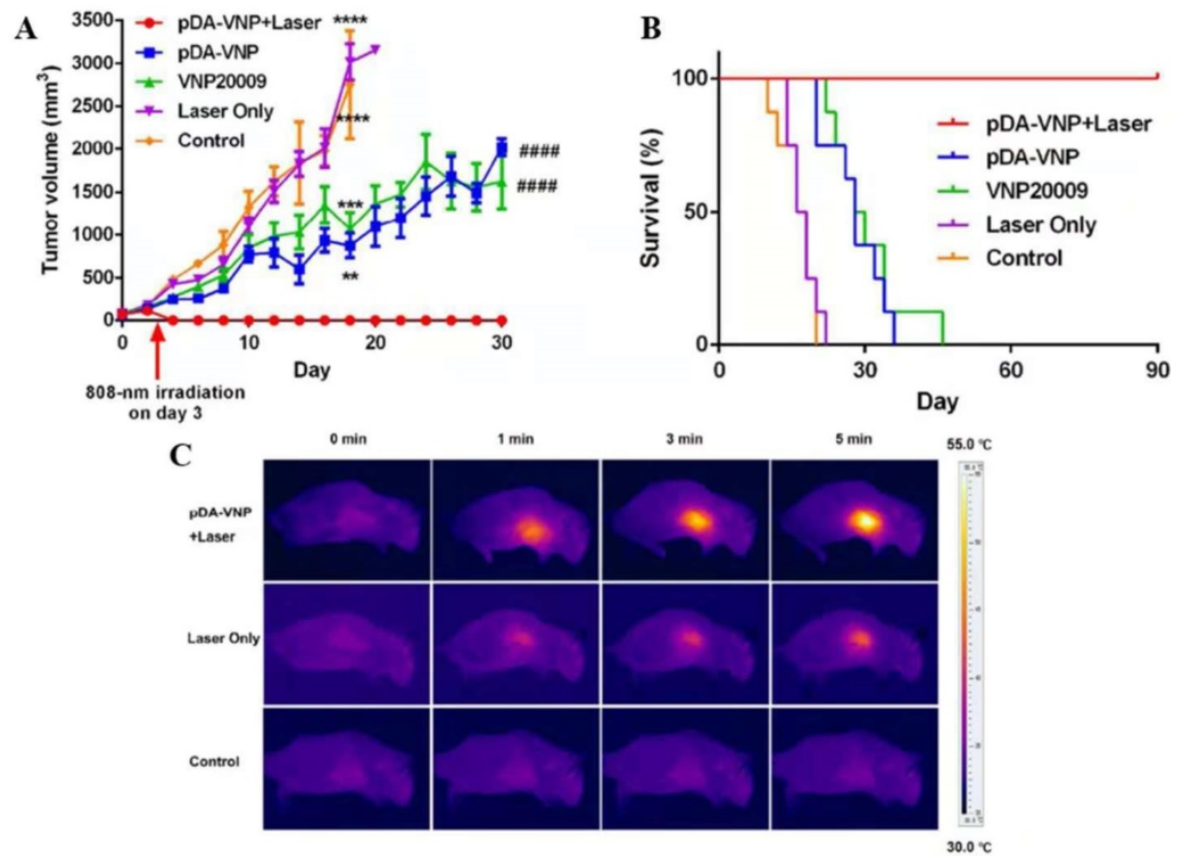

Figure 3. Combination of Salmonella and photothermal therapy in vivo. (A) Tumor volume after the indicated treatments. (B) Survival of mice after the indicated treatments. (C) Infrared thermal images of mice after the intravenous injection of PDA-VNP, followed by irradiation with a near-infrared laser $(* \mathrm{P}<0.05 ; * * \mathrm{P}<0.01 ; * * * \mathrm{P}<0.001$; ***** $<0.0001$; \#P $<0.05$; \#P < 0.01; \#\# < 0.001; \#\#P < 0.0001). Reproduced with permission from [52], copyright 2018 American Chemical Society.

A

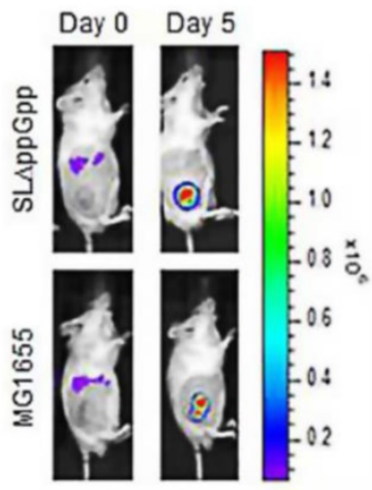

B

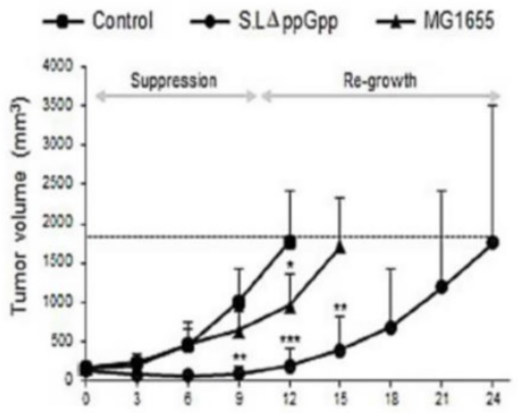

C
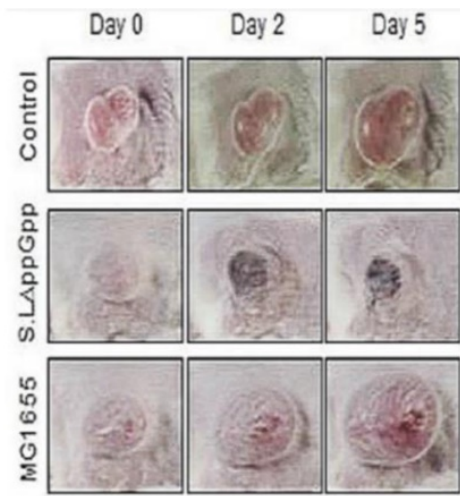

D

Control

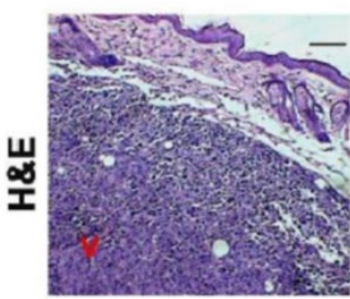

VNP

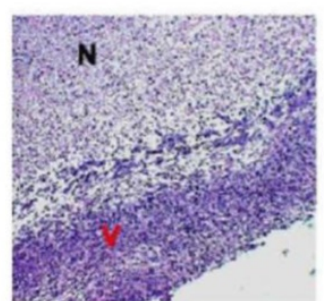

Figure 4. (A-C) Systemic injection of Salmonella ( $\Delta$ ppGpp) into tumor-bearing mice induces significant growth suppression compared with the effects of Escherichia coli (E. coli) (MG1655) injection [97]. (D) Systemic injection of Salmonella (VNP) into tumor-bearing mice induces significant growth suppression in histological examination [54]. (A) Distribution of bacteria visualized by in vivo bioluminescence imaging after the injection of bacteria expressing bacterial luciferase (lux). (B) The tumor volume was obviously decreased in the $\triangle$ ppGpp group compared with that in the other groups. (C) The shape of the tumor was noted before $(0$ days) and after treatment with PBS or bacteria ( 2 and 5 days). (D) Histologically, the tumors treated with VNP therapy showed extensive necrosis compared with the untreated control. N: necrotic areas, V: viable tumor cells. Reproduced with permission from [54, 97], copyright 2015, 2016 Ivyspring International Publisher. 

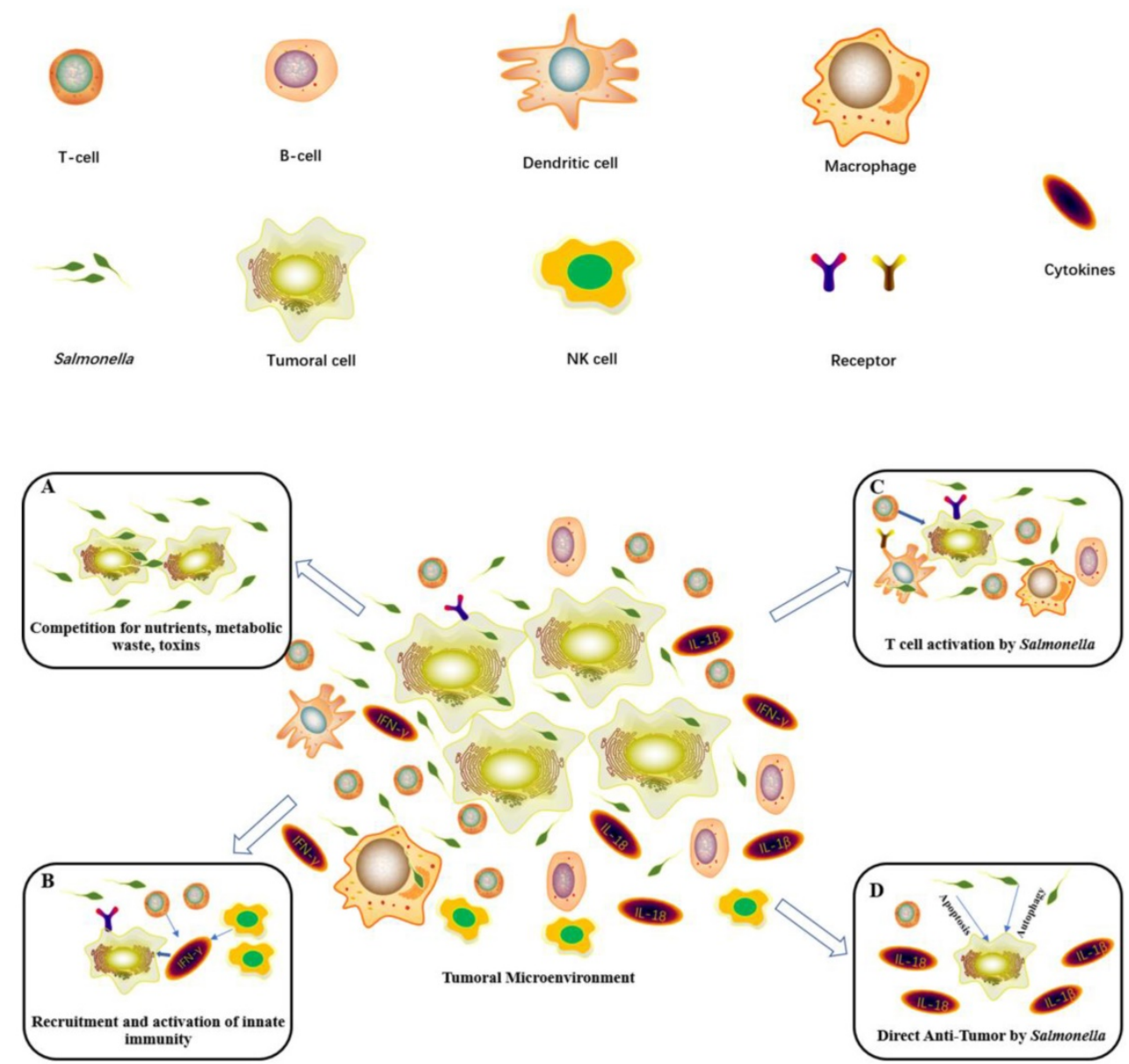

Figure 5. Diagram showing the main antitumor mechanisms induced by Salmonella. (A) Salmonella infection within the tumor microenvironment results in tumor growth inhibition and cell death. (B) Salmonella significantly upregulates IFN-Y and IFN-inducible chemokines to recruit NK cells and T cells to inhibit tumors. (C) Salmonella activates macrophages or dendritic cells by bacterial components. Then, these cells stimulate $T$ cell activities and cytokine expression. (D) Salmonella can lead to the death of tumor cells by inducing apoptosis and autophagy to activate caspase or downregulating the AKT/mTOR signaling pathway. Then, it will generate IL-1 $\beta$ and IL-18 to antitumors.

\section{Innate Immunity by Salmonella}

S. typhimurium is a pathogen that causes food poisoning in humans, resulting in gastroenteritis [65]. However, this pathogen can induce an immediate response mediated by the innate arm of the immune system followed by antigen-specific adaptive immunity. Some have proven that salmonellamediated tumor inhibition relies on the induction of the innate immune response through the toll-like receptor-myeloid differentiation primary response gene signaling pathway. Salmonella leads to the phenotypic and functional maturation of intratumoral myeloid cells, making these cells less suppressive and hence enhancing the antitumor immune response of the host. In vivo, the interferon- $\gamma$ (IFN) and IFN-induced chemokines CXCL9 (MIG) and CXCL10 (IP-10) showed increased expression in the tumor cells during salmonella treatment. IFN- $\gamma$ - and IFN-induced chemokines may be responsible for recruiting peripheral natural killer, neutrophils, macrophages, and T cells to the tumor (Figure 5B) [79-84].

\section{T Cell Activation by Salmonella}

Recently, researchers proposed that $\mathrm{T}$ cell activation by Salmonella may play a key role in salmonella-mediated antitumors (Figure 6)[85]. The bacterial components, such as lipopolysaccharide, lipoteichoic acid, and flagellin, could stimulate T cells to recognize and kill tumor cells at the primary site and prevent metastasis formation [84]. Salmonella replication and the lysis of tumor cells could increase the infiltration of CD4+ T cells and CD8+ T cells to enhance immune responses to tumor cells [86]. Salmonella-expressing cytokines could activate T cells to modulate host immunity and inhibit tumor growth. These results proved that the stimulated $\mathrm{T}$ cell activities play a significant role in tumor-targeted therapy by Salmonella (Figure 5C) $[87,88]$. The process of the $\mathrm{T}$ cell immune response could be activated by gap junctions. First, in both human and murine tumor cells, infection with Salmonella can induce the upregulation of connexin 43 (Cx43), a ubiquitous protein that forms gap junctions. These gap junctions transferred preprocessed antigenic peptides from the 
tumor cells to antigen-presenting dendritic cells (DCs), which then presented those peptides on their surfaces [89]. These peptides activated CD8+ T cells against the tumor [90-92]. B cells also play an important role in Salmonella-mediated antitumors. B cells can inhibit the dissemination of Salmonella to other healthy organs in Salmonella-mediated tumor models. In B cell-deficient mice, the bacterial loads of healthy organs were higher than those in wild-type mice [93]. Inflammation from bacteremia and cytokines was found in B cell-deficient mice after Salmonella treatment [79, 94]. However, the mechanism of this process is still unclear.

\section{Autophagy and Apoptosis by Salmonella}

Salmonella could induce tumor apoptosis with Salmonella accumulation at tumor sites (Figure 7)[73]. The induction of tumor cell apoptosis may have multiple mechanisms, including the stimulation of the immune response, secretion of toxins from bacteria and competition for nutrients. Salmonella may induce cell death via apoptosis and autophagic pathways by using an autophagy inhibitor and an apoptosis inhibitor. Salmonella can significantly decrease the factors that negatively regulate autophagy by the AKT/mTOR signaling pathway. Salmonella, on the other hand, could stimulate caspase- 1 by inflammasomes to induce tumor cell apoptosis. Then, this enzyme will cleave pro-IL-1 $\beta$ and pro-IL-18 to yield active IL-1 $\beta$ and IL-18 to antitumors [43]. Some data have suggested that infected tumor cells increased autophagy when apoptosis was blocked. Salmonella treatment efficiently induces both autophagy and apoptosis, which cooperate to lead to cancer cell death (Figure 5D)[95].

In summary, the Salmonella-induced immune response is a complex and systemic process. Salmonella induces the production of proinflammatory molecules and the activation of immune cells to change the tumor microenvironment. For decades, research has focused almost entirely on the cancer cell itself, ignoring complex biological interactions between the tumor and stroma in which the cell grows - the so-called tumor microenvironment. The change in the tumor microenvironment by Salmonella may be a key factor for the anticancer effect.
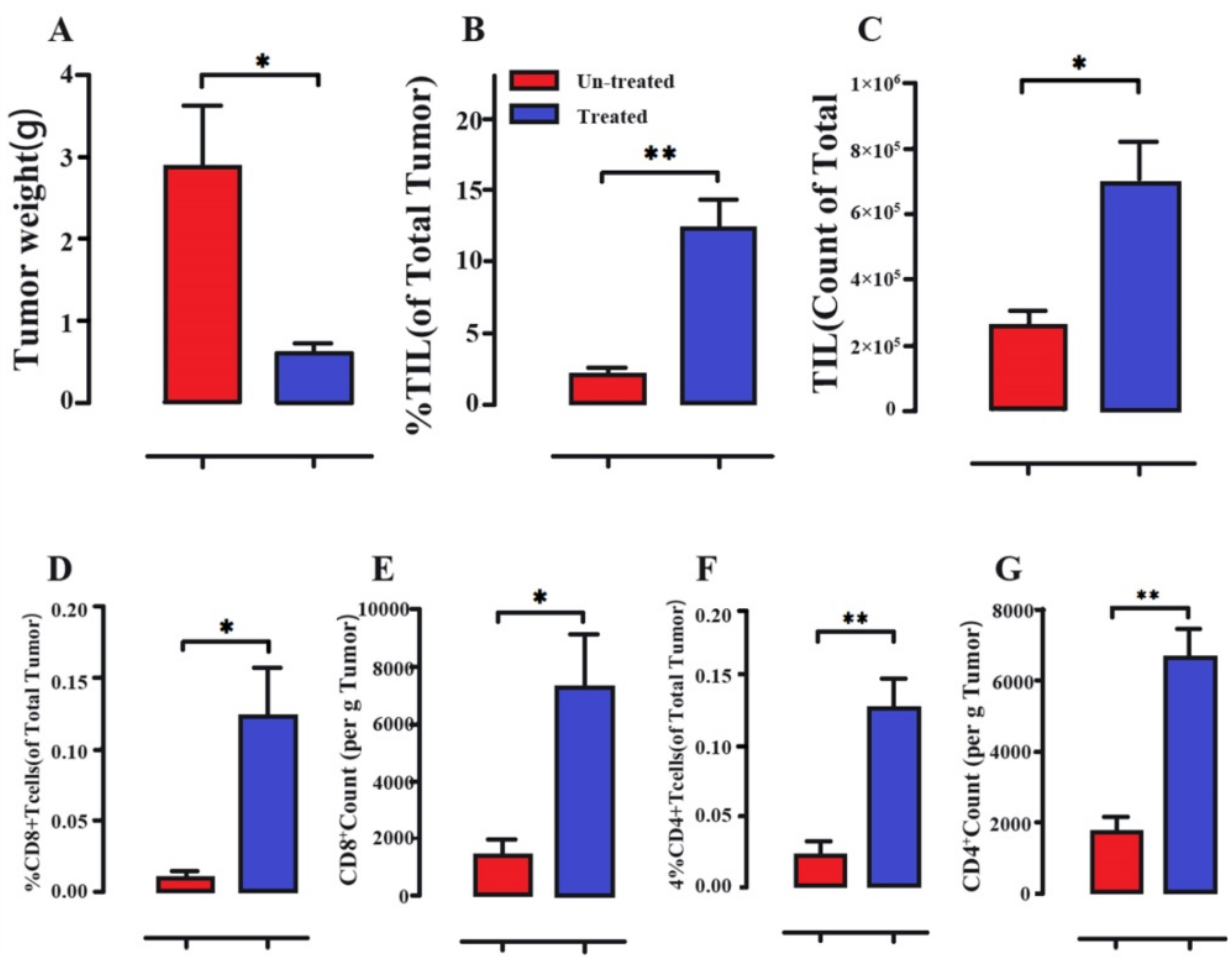

Figure 6. Immune cell activation of melanoma tumors following intraperitoneal treatment with a S. typhimurium strain. (A) Decreased tumor weights (B-G) Salmonella-treated mice obviously showed the increased percentage and absolute counts of tumor-infiltrating leukocytes (TIL), CD8+ T cells and CD4+ T cells. Reproduced with permission from [98], copyright 2018 Kaimala, Al-Sbiei, Cabral-Marques, Fernandez-Cabezudo and Al-Ramadi. 

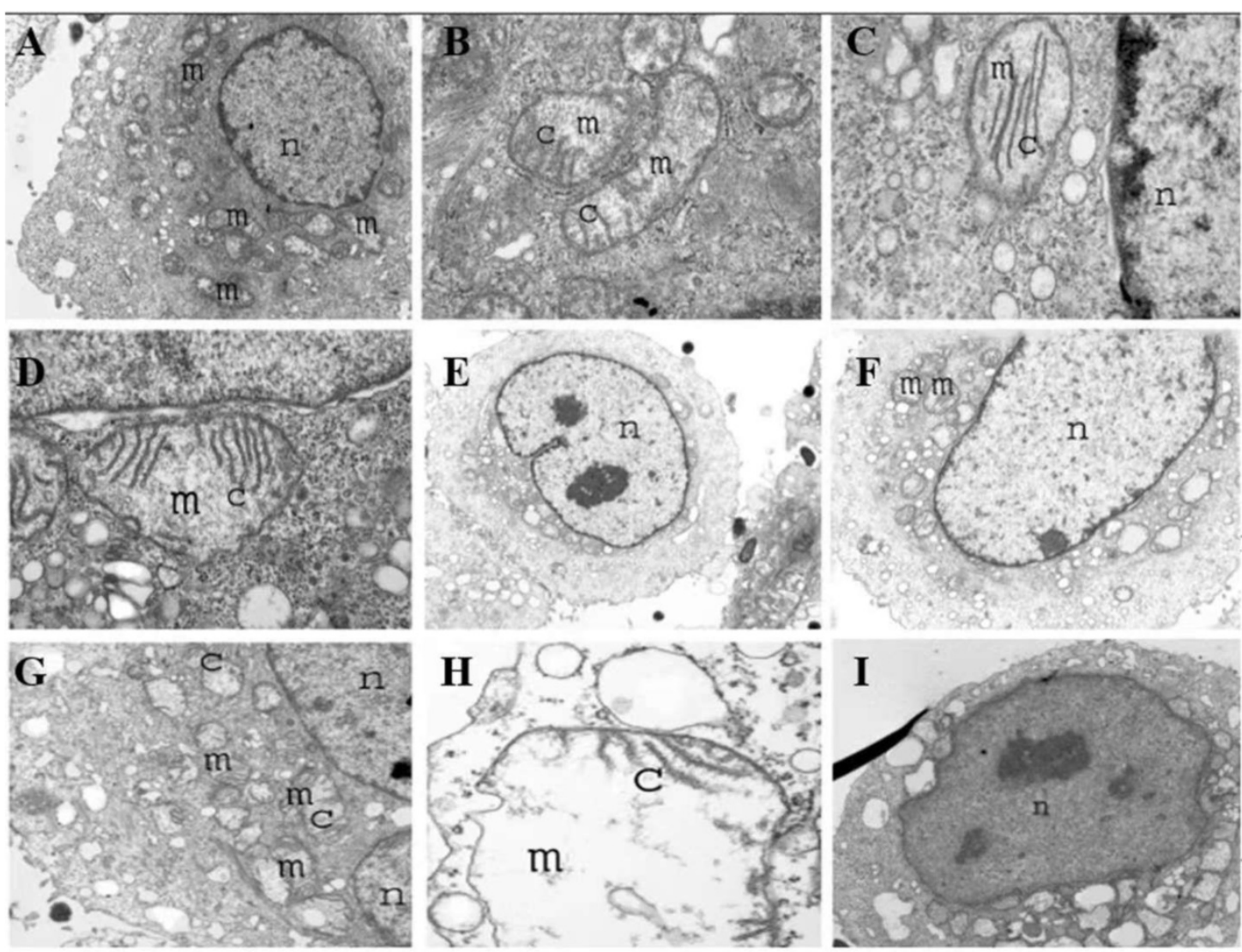

Figure 7. Transmission electron microscopy (TEM) of tumor cells infected with S. typhimurium at $1 \mathrm{~h}(\mathrm{~A}-\mathrm{D}), 4 \mathrm{~h}(\mathrm{E}-\mathrm{G})$, and $8 \mathrm{~h}(\mathrm{H}, \mathrm{I})$ displaying various degrees of mitochondria destruction as a result of Salmonella infection. Mitochondria are shown in which cristae are destroyed gradually, leaving a large empty space and vacuole. Tumor cells eventually become apoptotic over time. Reproduced with permission from [99], copyright 2007 Cambridge University Press

\section{Conclusion and Future Perspectives}

In this review, Salmonella-mediated antitumor therapy promoted significant tumor suppression and prolonged survival in many studies. Salmonellamediated antitumor therapy has some advantages over other therapies, including proliferation, self-targeting, and ease of genetic manipulation, which are engineered attenuated strains. These characteristics make Salmonella an ideal and novel strategy for anticancer therapy. However, at present, Salmonella-mediated antitumor therapy is still not deep enough, and many problems need to be solved in practice. For example, the results achieved in the phase I clinical trial were not satisfactory. We do not know the core of the change in the tumor microenvironment by Salmonella. It is complicated to understand the complex interactions between Salmonella, inflammatory reactions and host immunity to maximize the chances of therapeutic success. Combination therapies with Salmonella-mediated therapy and other tumor therapies enhance the curative effects in a synergistic fashion. This strategy is a hot topic for future research. BMCT may not replace or combine all tumor treatment methods but will provide a novel treatment strategy to fight against cancer [96].

\section{Acknowledgments}

This work was supported by Chinese National Natural Science Foundation (81771827) to Peng-Fei Rong and Graduate Freedom Exploration Project of Central South University, China(2018zzts954) to Ze Mi.

\section{Competing Interests}

The authors have declared that no competing interest exists.

\section{References}

1. Felgner S, Kocijancic D, Frahm M, Curtiss R, 3rd, Erhardt M, Weiss S. Optimizing Salmonella enterica serovar Typhimurium for bacteria-mediated tumor therapy. Gut microbes. 2016; 7: 171-7.

2. Howlader N, Noone A, Krapcho M, Garshell J, Miller D, Altekruse S, et al. SEER cancer statistics review, 1975-2012. Bethesda, MD: National Cancer Institute. 2015; 2015.

3. Cardoso F, Harbeck N, Fallowfield L, Kyriakides S, Senkus E, Group EGW. Locally recurrent or metastatic breast cancer: ESMO Clinical Practice Guidelines for diagnosis, treatment and follow-up. Annals of oncology. 2012; 23: vii11-vii9.

4. Barker HE, Paget JT, Khan AA, Harrington KJ. The tumour microenvironment after radiotherapy: mechanisms of resistance and recurrence. Nat Rev Cancer. 2015; 15: 409-25. 
5. Nguyen VH, Min JJ. Salmonella-Mediated Cancer Therapy: Roles and Potential. Nuclear medicine and molecular imaging. 2017; 51: 118-26.

6. Coley W. Contribution to the knowledgeofsarcoma. Am Surg. 1891; 14: 190.

7. McCarthy EF. The toxins of William B. Coley and the treatment of bone and soft-tissue sarcomas. The Iowa orthopaedic journal. 2006; $26: 154$.

8. Maletzki C, Linnebacher M, Kreikemeyer B, Emmrich J. Pancreatic cancer regression by intratumoural injection of live Streptococcus pyogenes in a syngeneic mouse model. Gut. 2008; 57: 483-91.

9. Zhu H, Li Z, Mao S, Ma B, Zhou S, Deng L, et al. Antitumor effect of sFlt-1 gene therapy system mediated by Bifidobacterium Infantis on Lewis lung cancer in mice. Cancer gene therapy. 2011; 18: 884

10. Agrawal N, Bettegowda C, Cheong I, Geschwind J-F, Drake CG, Hipkiss EL, et al. Bacteriolytic therapy can generate a potent immune response against experimental tumors. Proceedings of the National Academy of Sciences. 2004; 101: 15172-7.

11. Yoon W, Yoo Y, Chae YS, Kee SH, Kim BM. Therapeutic advantage of genetically engineered Salmonella typhimurium carrying short hairpin RNA against inhibin alpha subunit in cancer treatment. Ann Oncol. 2018; 29: 2010-7.

12. Wang Y, Chen J, Tang B, Zhang X, Hua ZC. Systemic administration of attenuated Salmonella typhimurium in combination with interleukin-21 for cancer therapy. Molecular and clinical oncology. 2013; 1: 461-5.

13. Lee $\mathrm{CH}, \mathrm{Wu} \mathrm{CL}$, Tai YS, Shiau AL. Systemic administration of attenuated Salmonella choleraesuis in combination with cisplatin for cancer therapy. Molecular therapy : the journal of the American Society of Gene Therapy. 2005; 11: 707-16

14. Eisenstark A. A Geneticist's View of Prostate Cancer: Prostate Cancer Treatment Considerations. Advances in experimental medicine and biology. 2018; 1095: 125-9.

15. Ben-Jacob E. Engineering Trojan-horse bacteria to fight cancer. Blood. 2013; 122: 619-20.

16. Na HS, Kim HJ, Lee H-C, Hong Y, Rhee JH, Choy HE. Immune response induced by Salmonella typhimurium defective in ppGpp synthesis. Vaccine. 2006; 24: 2027-34.

17. Forbes NS. Engineering the perfect (bacterial) cancer therapy. Nature Reviews Cancer. 2010; 10: 785.

18. Liu X, Jiang S, Piao L, Yuan F. Radiotherapy combined with an engineered Salmonella typhimurium inhibits tumor growth in a mouse model of colon cancer. Experimental animals. 2016; 65: 413-8.

19. Ganai S, Arenas R, Forbes N. Tumour-targeted delivery of TRAIL using Salmonella typhimurium enhances breast cancer survival in mice. British journal of cancer. 2009; 101: 1683

20. Yang CI, Chang WW, Lin ST, Chen MC, Lee CH. Salmonella Overcomes Drug Resistance in Tumor through P-glycoprotein Downregulation. International journal of medical sciences. 2018; 15: 574-9.

21. Kawaguchi $\mathrm{K}$, Igarashi $\mathrm{K}$, Murakami $\mathrm{T}$, Kiyuna $\mathrm{T}$, Zhao M, Zhang $\mathrm{Y}$, et al. Salmonella typhimurium A1-R targeting of a chemotherapy-resistant BRAF-V600E melanoma in a patient-derived orthotopic xenograft (PDOX) model is enhanced in combination with either vemurafenib or temozolomide. Cell cycle (Georgetown, Tex). 2017; 16: 1288-94.

22. Jia LJ, Wei DP, Sun QM, Jin GH, Li SF, Huang Y, et al. Tumor-targeting Salmonella typhimurium improves cyclophosphamide chemotherapy at maximum tolerated dose and low-dose metronomic regimens in a murine melanoma model. International journal of cancer. 2007; 121: 666-74.

23. Wang CZ, Kazmierczak RA, Eisenstark A. Strains, Mechanism, and Perspective: Salmonella-Based Cancer Therapy. International journal of microbiology. 2016; 2016: 5678702

24. Drees JJ, Mertensotto MJ, Augustin LB, Schottel JL, Saltzman DA. Vasculature Disruption Enhances Bacterial Targeting of Autochthonous Tumors. J Cancer. 2015; 6: 843-8.

25. Ning BT, Yu B, Chan S, Chan JL, Huang JD, Chan GC. Treatment of Neuroblastoma with an Engineered "Obligate" Anaerobic Salmonella typhimurium Strain YB1. J Cancer. 2017; 8: 1609-18.

26. Toso JF, Gill VJ, Hwu P, Marincola FM, Restifo NP, Schwartzentruber DJ, et al. Phase I study of the intravenous administration of attenuated Salmonella typhimurium to patients with metastatic melanoma. Journal of clinical oncology: official journal of the American Society of Clinical Oncology. 2002; 20: 142.

27. Clairmont C, Lee K, Pike J, Ittensohn M, Low K, Pawelek J, et al. Biodistribution and genetic stability of the novel antitumor agent VNP20009, a genetically modified strain of Salmonella typhimuvium. Journal of Infectious Diseases. 2000; 181: 1996-2002.

28. Quintero D, Carrafa J, Vincent L, Bermudes D. EGFR-targeted Chimeras of Pseudomonas ToxA released into the extracellular milieu by attenuated Salmonella selectively kill tumor cells. Biotechnology and bioengineering. 2016; 113: 2698-711.
29. Xu W, Zhou T, Zhou J, Qiang Z, Zhang J, Hua Z. Attenuated Salmonella VNP20009 mutant (DeltahtrA) is a promising candidate for bacteria-mediated tumour therapy in hosts with TNFR1 deficiency. Lett Appl Microbiol. 2018; 67: 97-103.

30. Broadway KM, Modise T, Jensen RV, Scharf BE. Complete genome sequence of Salmonella enterica serovar Typhimurium VNP20009, a strain engineered for tumor targeting. Journal of biotechnology. 2014; 192: 177-8.

31. Zhao M, Yang M, Li X-M, Jiang P, Baranov E, Li S, et al. Tumor-targeting bacterial therapy with amino acid auxotrophs of GFP-expressing Salmonella typhimurium. Proceedings of the National Academy of Sciences. 2005; 102: 755-60

32. Momiyama M ZM, Kimura H, Tran B, Chishima T, BouvetM, et al. Inhibition and eradication of human glioma with tumor-targeting Salmonella typhimurium in an orthotopic nude-mouse model. Cell cycle (Georgetown, Tex). 2012; 11: 628-32.

33. Zhao M, Geller J, Ma H, Yang M, Penman S, Hoffman RM. Monotherapy with a tumor-targeting mutant of Salmonella typhimurium cures orthotopic metastatic mouse models of human prostate cancer. Proceedings of the National Academy of Sciences. 2007; 104: 10170-4.

34. Yam C, Zhao M, Hayashi K, Ma H, Kishimoto H, McElroy M, et al. Monotherapy with a tumor-targeting mutant of $\mathrm{S}$. typhimurium inhibits liver metastasis in a mouse model of pancreatic cancer. Journal of Surgical Research. 2010; 164: 248-55.

35. Hiroshima Y, Zhang Y, Zhao M, Zhang N, Murakami T, Maawy A, et al. Tumor-targeting Salmonella typhimurium A1-R in combination with Trastuzumab eradicates HER-2-positive cervical cancer cells in patient-derived mouse models. PloS one. 2015; 10: e0120358.

36. Miyake K, Kiyuna T, Miyake M, Zhao M, Wangsiricharoen S, Kawaguchi $\mathrm{K}$, et al. Tumor-targeting Salmonella typhimurium A1-R overcomes partial carboplatinum-resistance of a cancer of unknown primary (CUP). Tissue and Cell. 2018; 54: 144-9.

37. Kiyuna T, Tome $Y$, Murakami T, Miyake K, Igarashi K, Kawaguchi K, et al. A combination of irinotecan/cisplatinum and irinotecan/temozolomide or tumor-targeting Salmonella typhimurium A1-R arrest doxorubicin-and temozolomide-resistant myxofibrosarcoma in a PDOX mouse model. Biochemical and biophysical research communications. 2018; 505: 733-9.

38. Yano S, Zhang Y, Zhao M, Hiroshima Y, Miwa S, Uehara F, et al. Tumor-targeting Salmonella typhimurium A1-R decoys quiescent cancer cells to cycle as visualized by FUCCI imaging and become sensitive to chemotherapy. Cell cycle (Georgetown, Tex). 2014; 13: 3958-63.

39. Yano S, Zhang Y, Miwa S, Tome Y, Hiroshima Y, Uehara F, et al. Spatial-temporal FUCCI imaging of each cell in a tumor demonstrates locational dependence of cell cycle dynamics and chemoresponsiveness. Cell cycle (Georgetown, Tex). 2014; 13: 2110-9.

40. Yano S, Takehara K, Zhao M, Tan Y, Han Q, Li S, et al. Tumor-specific cell-cycle decoy by Salmonella typhimurium A1-R combined with tumor-selective cell-cycle trap by methioninase overcome tumor intrinsic chemoresistance as visualized by FUCCI imaging. Cell cycle (Georgetown, Tex). 2016; 15: 1715-23.

41. Yun M, Pan S, Jiang SN, Nguyen VH, Park SH, Jung CH, et al. Effect of Salmonella treatment on an implanted tumor (CT26) in a mouse model. J Microbiol. 2012; 50: 502-10.

42. Kim J-E, Phan TX, Nguyen VH, Dinh-Vu H-V, Zheng JH, Yun M, et al. Salmonella typhimurium suppresses tumor growth via the pro-inflammatory cytokine interleukin-1 $\beta$. Theranostics. 2015; 5: 1328 .

43. Phan TX, Nguyen VH, Duong MTQ, Hong Y, Choy HE, Min JJ. Activation of inflammasome by attenuated Salmonella typhimurium in bacteria-mediated cancer therapy. Microbiology and immunology. 2015; 59: 664-75.

44. Jiang S-N, Park S-H, Lee HJ, Zheng JH, Kim H-S, Bom H-S, et al. Engineering of bacteria for the visualization of targeted delivery of a cytolytic anticancer agent. Molecular Therapy. 2013; 21: 1985-95.

45. Le UN, Kim H-S, Kwon J-S, Kim MY, Nguyen VH, Jiang SN, et al. Engineering and visualization of bacteria for targeting infarcted myocardium. Molecular Therapy. 2011; 19: 951-9.

46. Roider E, Jellbauer S, Kohn B, Berchtold C, Partilla M, Busch DH, et al. Invasion and destruction of a murine fibrosarcoma by Salmonella-induced effector CD8 T cells as a therapeutic intervention against cancer. Cancer Immunol Immunother. 2011; 60: 371-80.

47. Xiong G, Husseiny MI, Song L, Erdreich-Epstein A, Shackleford GM, Seeger RC, et al. Novel cancer vaccine based on genes of Salmonella pathogenicity island 2. International journal of cancer. 2010; 126: 2622-34.

48. Panthel K, Meinel KM, Domenech VE, Retzbach H, Igwe EI, Hardt WD, et al. Salmonella pathogenicity island 2-mediated overexpression of chimeric $\mathrm{SspH} 2$ proteins for simultaneous induction of antigen-specific CD4 and CD8 T cells. Infect Immun. 2005; 73: 334-41. 
49. Huebener N, Fest S, Strandsby A, Michalsky E, Preissner R, Zeng Y, et al. A rationally designed tyrosine hydroxylase DNA vaccine induces specific antineuroblastoma immunity. Mol Cancer Ther. 2008; 7: 2241-51.

50. Barak Y, Thorne SH, Ackerley DF, Lynch SV, Contag CH, Matin A. New enzyme for reductive cancer chemotherapy, YieF, and its improvement by directed evolution. Mol Cancer Ther. 2006; 5: 97-103.

51. Yu B, Yang M, Shi L, Yao Y, Jiang Q, Li X, et al. Explicit hypoxia targeting with tumor suppression by creating an "obligate" anaerobic Salmonella Typhimurium strain. Sci Rep. 2012; 2: 436.

52. Chen W, Wang $Y$, Qin $M$, Zhang $X$, Zhang $Z$, Sun $X$, et al. Bacteria-Driven Hypoxia Targeting for Combined Biotherapy and Photothermal Therapy. ACS Nano. 2018.

53. Wang Y, Zhou Z, Chen W, Qin M, Zhang Z, Gong T, et al. Potentiating bacterial cancer therapy using hydroxychloroquine liposomes. J Control Release. 2018; 280: 39-50.

54. Chen J, Qiao Y, Tang B, Chen G, Liu X, Yang B, et al. Modulation of Salmonella Tumor-Colonization and Intratumoral Anti-angiogenesis by Triptolide and Its Mechanism. Theranostics. 2017; 7: 2250-60.

55. Zhao C, He J, Cheng H, Zhu Z, Xu H. Enhanced therapeutic effect of an antiangiogenesis peptide on lung cancer in vivo combined with salmonella VNP20009 carrying a Sox2 shRNA construct. J Exp Clin Cancer Res. 2016; 35: 107

56. Kawaguchi K, Higuchi T, Li S, Han Q, Tan Y, Igarashi K, et al. Combination therapy of tumor-targeting Salmonella typhimurium A1-R and oral recombinant methioninase regresses a BRAF-V600E-negative melanoma. Biochem Biophys Res Commun. 2018.

57. Miyake K, Kawaguchi K, Miyake M, Zhao M, Kiyuna T, Igarashi K, et al. Tumor-targeting Salmonella typhimurium A1-R suppressed an imatinib-resistant gastrointestinal stromal tumor with c-kit exon 11 and 17 mutations. Heliyon. 2018; 4: e00643.

58. Kawaguchi K, Miyake K, Zhao M, Kiyuna T, Igarashi K, Miyake M, et al. Tumor targeting Salmonella typhimurium A1-R in combination with gemcitabine (GEM) regresses partially GEM-resistant pancreatic cancer patient-derived orthotopic xenograft (PDOX) nude mouse models. Cell cycle (Georgetown, Tex). 2018.

59. Murakami T, Hiroshima Y, Zhang Y, Zhao M, Kiyuna T, Hwang HK, et al. Tumor-Targeting Salmonella typhimurium A1-R Promotes Tumoricidal CD8(+) T Cell Tumor Infiltration and Arrests Growth and Metastasis in a Syngeneic Pancreatic-Cancer Orthotopic Mouse Model. J Cell Biochem. 2018; 119: 634-9.

60. Igarashi K, Kawaguchi K, Kiyuna T, Miyake K, Miyake M, Li S, et al. Tumor-targeting Salmonella typhimurium A1-R combined with recombinant methioninase and cisplatinum eradicates an osteosarcoma cisplatinum-resistant lung metastasis in a patient-derived orthotopic xenograft (PDOX) mouse model: decoy, trap and kill chemotherapy moves toward the clinic. Cell cycle (Georgetown, Tex). 2018; 17: 801-9.

61. Jiang SN, Phan TX, Nam TK, Nguyen VH, Kim HS, Bom HS, et al. Inhibition of tumor growth and metastasis by a combination of Escherichia coli-mediated cytolytic therapy and radiotherapy. Molecular therapy : the journal of the American Society of Gene Therapy. 2010; 18: 635-42.

62. Jia LJ, Wei DP, Sun QM, Huang Y, Wu Q, Hua ZC. Oral delivery of tumor-targeting Salmonella for cancer therapy in murine tumor models. Cancer science. 2007; 98: 1107-12

63. Chang WW, Lai CH, Chen MC, Liu CF, Kuan YD, Lin ST, et al. Salmonella enhance chemosensitivity in tumor through connexin 43 upregulation. International journal of cancer. 2013; 133: 1926-35.

64. Saltzman D, Augustin L, Leonard A, Mertensotto M, Schottel J. Low dose chemotherapy combined with attenuated Salmonella decreases tumor burden and is less toxic than high dose chemotherapy in an autochthonous murine model of breast cancer. Surgery. 2018; 163: 509-14.

65. Mercado-Lubo R, Zhang Y, Zhao L, Rossi K, Wu X, Zou Y, et al. A Salmonella nanoparticle mimic overcomes multidrug resistance in tumours. Nature communications. 2016; 7: 12225.

66. Harrington K, Billingham L, Brunner T, Burnet N, Chan C, Hoskin P, et al. Guidelines for preclinical and early phase clinical assessment of novel radiosensitisers. British journal of cancer. 2011; 105: 628.

67. Camphausen $\mathrm{K}$, Tofilon PJ. Combining radiation and molecular targeting in cancer therapy. Cancer biology \& therapy. 2004; 3: 247-50.

68. Twyman-Saint Victor C, Rech AJ, Maity A, Rengan R, Pauken KE, Stelekati E, et al. Radiation and dual checkpoint blockade activate non-redundant immune mechanisms in cancer. Nature. 2015; 520: 373-7.

69. Mei Y, Zhao L, Liu Y, Gong H, Song Y, Lei L, et al. Combining DNA Vaccine and AIDA-1 in Attenuated Salmonella Activates Tumor-Specific CD4(+) and CD8(+) T-cell Responses. Cancer Immunol Res. 2017; 5: 503-14

70. Roland KL, Brenneman KE. Salmonella as a vaccine delivery vehicle. Expert review of vaccines. 2013; 12: 1033-45.
71. Lee C-H, Hsieh J-L, Wu C-L, Hsu P-Y, Shiau A-L. T cell augments the antitumor activity of tumor-targeting Salmonella. Applied microbiology and biotechnology. 2011; 90: 1381-8.

72. Felgner S, Kocijancic D, Frahm M, Heise U, Rohde M, Zimmermann K, et al. Engineered Salmonella enterica serovar Typhimurium overcomes limitations of anti-bacterial immunity in bacteria-mediated tumor therapy. Oncoimmunology. 2018; 7: e1382791.

73. Lee C-H. Engineering bacteria toward tumor targeting for cancer treatment: current state and perspectives. Applied microbiology and biotechnology. 2012; 93: 517-23.

74. Kasinskas RW, Forbes NS. Salmonella typhimurium specifically chemotax and proliferate in heterogeneous tumor tissue in vitro. Biotechnology and bioengineering. 2006; 94: 710-21.

75. Weiss SL. Salmonella-allies in the fight against cancer. Journal of Molecular Medicine. 2010; 88: 763-73.

76. Stritzker J, Weibel S, Seubert C, Götz A, Tresch A, Van Rooijen N, et al. Enterobacterial tumor colonization in mice depends on bacterial metabolism and macrophages but is independent of chemotaxis and motility. International Journal of Medical Microbiology. 2010; 300: 449-56.

77. Low KB, Ittensohn M, Le T, Platt J, Sodi S, Amoss M, et al. Lipid A mutant Salmonella with suppressed virulence and TNFa induction retain tumor-targeting in vivo. Nature biotechnology. 1999; 17: 37.

78. Sznol M, Lin SL, Bermudes D, Zheng L-m, King I. Use of preferentially replicating bacteria for the treatment of cancer. The Journal of clinical investigation. 2000; 105: 1027-30.

79. Grille S, Moreno M, Bascuas T, Marques JM, Munoz N, Lens D, et al. Salmonella enterica serovar Typhimurium immunotherapy for B-cell lymphoma induces broad anti-tumour immunity with therapeutic effect. Immunology. 2014; 143: 428-37.

80. Barak Y, Schreiber F, Thorne SH, Contag CH, Debeer D, Matin A. Role of nitric oxide in Salmonella typhimurium-mediated cancer cell killing. BMC Cancer. 2010; 10: 146.

81. Leigh ND, Bian G, Ding X, Liu H, Aygun-Sunar S, Burdelya LG, et al. A flagellin-derived toll-like receptor 5 agonist stimulates cytotoxic lymphocyte-mediated tumor immunity. PloS one. 2014; 9: e85587.

82. Kupz A, Curtiss III R, Bedoui S, Strugnell RA. In vivo IFN-ץ secretion by NK cells in response to Salmonella typhimurium requires NLRC4 inflammasomes. PloS one. 2014; 9: e97418.

83. Lee C-H, Wu C-L, Shiau A-L. Toll-like receptor 4 mediates an antitumor host response induced by Salmonella choleraesuis. Clinical Cancer Research. 2008; 14: 1905-12.

84. Yoon W, Choi JH, Kim S, Park YK. Engineered Salmonella typhimurium expressing E7 fusion protein, derived from human papillomavirus, inhibits tumor growth in cervical tumor-bearing mice. Biotechnology letters. 2014; 36: 349-56.

85. Maybeno M, Redeker A, Welten SP, Peters B, Loughhead SM, Schoenberger SP, et al. Polyfunctional CD4+ T cell responses to immunodominant epitopes correlate with disease activity of virulent Salmonella. PloS one. 2012; 7: e43481.

86. Avogadri F, Martinoli C, Petrovska L, Chiodoni C, Transidico P, Bronte $\mathrm{V}$, et al. Cancer immunotherapy based on killing of Salmonella-infected tumor cells. Cancer research. 2005; 65: 3920-7.

87. Binder DC, Engels B, Arina A, Yu P, Slauch JM, Fu Y-X, et al. Antigen-specific bacterial vaccine combined with anti-PD-L1 rescues dysfunctional endogenous $\mathrm{T}$ cells to reject long-established cancer. Cancer immunology research. 2013; 1: 123-33.

88. Manuel ER, Blache CA, Paquette R, Kaltcheva TI, Ishizaki H, Ellenhorn JD, et al. Enhancement of cancer vaccine therapy by systemic delivery of a tumor-targeting Salmonella-based STAT3 shRNA suppresses the growth of established melanoma tumors. Cancer research. 2011; 71: 4183-91.

89. Shilling DA, Smith MJ, Tyther R, Sheehan D, England K, Kavanagh EG, et al. Salmonella typhimurium stimulation combined with tumour-derived heat shock proteins induces potent dendritic cell anti-tumour responses in a murine model. Clin Exp Immunol. 2007; 149: 109-16.

90. Jellbauer S, Panthel K, Hetrodt JH, Russmann H. CD8 T-cell induction against vascular endothelial growth factor receptor 2 by Salmonella for vaccination purposes against a murine melanoma. PloS one. 2012; 7: e34214.

91. Stark FC, Sad S, Krishnan L. Intracellular bacterial vectors that induce CD8(+) T cells with similar cytolytic abilities but disparate memory phenotypes provide contrasting tumor protection. Cancer Res. 2009; 69: 4327-34.

92. Saccheri F, Pozzi C, Avogadri F, Barozzi S, Faretta M, Fusi P, et al. Bacteria-induced gap junctions in tumors favor antigen cross-presentation and antitumor immunity. Science translational medicine. 2010; 2: 44ra57-44ra57. 
93. Lee C-H, Hsieh J-L, Wu C-L, Hsu H-C, Shiau A-L. B cells are required for tumor-targeting Salmonella in host. Applied microbiology and biotechnology. 2011; 92: 1251-60.

94. Reid RR, Prodeus AP, Khan W, Hsu T, Rosen FS, Carroll MC. Endotoxin shock in antibody-deficient mice: unraveling the role of natural antibody and complement in the clearance of lipopolysaccharide. The Journal of Immunology. 1997; 159: 970-5.

95. Chang WW, Lee $\mathrm{CH}$. Salmonella as an innovative therapeutic antitumor agent. International journal of molecular sciences. 2014; 15: 14546-54.

96. Din MO, Danino T, Prindle A, Skalak M, Selimkhanov J, Allen K, et al. Synchronized cycles of bacterial lysis for in vivo delivery. Nature. 2016; 536: 81-5.

97. Kim JE, Phan TX, Nguyen VH, Dinh-Vu HV, Zheng JH, Yun M, et al. Salmonella typhimurium Suppresses Tumor Growth via the Pro-Inflammatory Cytokine Interleukin-1beta. Theranostics. 2015; 5: 1328-42.

98. Kaimala S, Al-Sbiei A, Cabral-Marques O, Fernandez-Cabezudo MJ, Al-Ramadi BK. Attenuated Bacteria as Immunotherapeutic Tools for Cancer Treatment. Frontiers in oncology. 2018; 8: 136.

99. Zhong Z, Kazmierczak RA, Dino A, Khreis R, Eisenstark A, Schatten H. Salmonella-host cell interactions, changes in host cell architecture, and destruction of prostate tumor cells with genetically altered Salmonella. Microsc Microanal. 2007; 13: 372-83. 